\title{
A New Strategy of bi-Alkali Metal Doping to Design Boron Phosphide Nanocages of High Nonlinear Optical Response with Better Thermodynamic Stability
}

\author{
Rimsha Baloach \\ University of Education \\ Khurshid Ayub \\ University of Education \\ Tariq Mahmood \\ University of Education \\ Anila Asif \\ University of Education \\ Sobia Tabassum \\ University of Education \\ Mazhar Amjad Gilani ( $\square$ mazhargilani@cuilahore.edu.pk) \\ University of Education
}

\section{Original Research Full Papers}

Keywords: Boron phosphide (B12P12), Bi-alkali metal doping, Nonlinear optical response (NLO), Density functional theory

Posted Date: February 11th, 2021

DOI: https://doi.org/10.21203/rs.3.rs-207373/v1

License: (c) (i) This work is licensed under a Creative Commons Attribution 4.0 International License. Read Full License

Version of Record: A version of this preprint was published at Journal of Inorganic and Organometallic Polymers and Materials on April 16th, 2021. See the published version at https://doi.org/10.1007/s10904-021-02000-6. 


\section{A New Strategy of bi-Alkali Metal Doping to Design Boron Phosphide Nanocages of High Nonlinear Optical Response with Better Thermodynamic Stability}

\section{ABSTRACT:}

Nonlinear optical materials possess high rank in fields of optics owing to their impacts, utilization and extended applications in industrial sector. Therefore, design of molecular systems with high nonlinear optical response along with high thermodynamic stability is a dire need of this era. Hence, the present study involves investigation of bi-alkali metal doped boron phosphide nanocages $\mathrm{M}_{2} @ \mathrm{~B}_{12} \mathrm{P}_{12}(\mathrm{M}=\mathrm{Li}, \mathrm{Na}, \mathrm{K})$ in search of stable nonlinear optical materials. The investigation includes execution of geometrical and opto-electronic properties of complexes by means of density functional theory (DFT) computations. Bi-doped alkali metal atoms introduce excess of electrons in the host $\mathrm{B}_{12} \mathrm{P}_{12}$ nanocage. These electrons contribute towards the formation of new HOMO, thus reducing HOMO-LUMO gaps. The reduced HOMO-LUMO gap ranges from $0.63 \mathrm{eV}$ to $3.69 \mathrm{eV}$. The diffused excess electrons also come up with increased hyperpolarizability values of complexes i.e. up to $4.0 \times 10^{4} \mathrm{au}$. TD-DFT calculations have been performed to examine crucial transition states and for UV-VIS analysis. IR and DOS spectra have been plotted to support our obtained results. Non covalent interaction (NCI) calculations along with quantum theory of the atoms in molecules (QTAIM) analysis were carried out to understand the bonding interactions between alkali metal atoms and $\mathrm{B}_{12} \mathrm{P}_{12}$ nanocage. All obtained results suggest bi-alkali metal doped nanocages as exceptionally stable materials with improved NLO response and superb candidates for their vast applications in optics.

Keywords: Boron phosphide $\left(\mathrm{B}_{12} \mathrm{P}_{12}\right)$; Bi-alkali metal doping; Nonlinear optical response (NLO); Density functional theory 


\section{Introduction}

Nonlinear optical materials play important roles in this modern era of optics with their limitless utilization in different fields of science and technology[1]. They own numerous applications in the fields of modern computing, optical data storage, telecommunication, and photonics[2][3][4]. Furthermore, they also find their potential uses in adsorption[5], laser technology, waveguides, gyroscopes, and scanners as well[6][7][8][9]. At present, their use has been extended in designing of catalysts [10], pulse wave sensors[9], field-effect transistors[11], luminescent materials[12] and light emitting diodes[13]. In addition,, these materials are widely used in signal processing[14] logical technologies, and holographic imaging[15]. All these reported applications highlight the prime need to design new NLO materials for academic and industrial fields.

At present, various promising materials have been reported possessing outstanding NLO properties. These materials include inorganic fullerenes[16], donor- $\pi$ bridge-acceptor systems, chiral $\pi$ conjugated molecules[17]. Most recently, inorganic NLO crystals[18][19], carbon dots[20], octupolar molecules[21], graphidyne nanosheets[22], metal organic frameworks[23] multi-decker sandwich clusters[24]. Hyperpolarizability $\left(\beta_{t o t}\right)$ is the key feature to characterize the performance of NLO materials.[25]

Numerous studies have been reported to explore inorganic fullerenes $(\mathrm{XY})_{\mathrm{n}}$ as they possess unique properties and find extensive applications to design optoelectronic devices. To date, various fullerenes $(\mathrm{XY})_{\mathrm{n}}$ from group III-V have been synthesized by different experimental methods[26]. Carbothermal reduction, chemical vapor deposition and direct nitridation[27] solution growth method[28] are some of these techniques. Molecular simulations show that $(\mathrm{XY})_{\mathrm{n}}[\mathrm{X}=\mathrm{Al}, \mathrm{B} ; \mathrm{Y}=\mathrm{N}, \mathrm{P} ; \mathrm{n}=12]$ are the most stable structures. Fullerenes are semiconductors with wide HOMO-LUMO gap[29][30]. Usually, fullerenes are non-responsive towards NLO 
response and scientists have introduced numerous strategies to induce NLO response by both experimental and theoretical techniques. These strategies include doping[31], electron pushpull mechanism[32], extensive $\pi$ conjugation[33], utilization of bond length alteration theory (BLAT)[34], substitution effect[35], introduction of electron acceptor/donor group[36] and consideration of diradical character of materials[37].

Recently, Li et al. reported an effective strategy where diffused excess electrons are introduced in materials to increase their NLO response[38][39]. Fullerenes hold centrosymmetric structure therefore; they have zero dipole moment and hyperpolarizability $\left(\beta_{0}\right)$. The introduction of diffused excess electrons causes remarkable increase in hyperpolarizability, efficiently narrows down HOMO-LUMO gap and results in increased NLO response[40]. Certainly, doping of foreign metals is an efficient strategy to induce excess electrons in materials. Alkali metals have low ionization potential, therefore valence electrons from these metal atoms are easily diffused out to act as excess electrons in materials. This technique is being frequently used to design high performance[41] NLO materials. Literature reveals that lithium doping on $\mathrm{B}_{10} \mathrm{H}_{14}$ framework leads to considerable increase in hyperpolarizability $\left(2.31 \times 10^{4} \mathrm{au}\right)$ because of diffused excess electrons of Li atom[42]. Huang et al. have studied alkali metal doped AlN nanocages and proved that hyperpolarizability of the resultant complex ( $\left.\mathrm{Li} @ \mathrm{~b}_{66}-\mathrm{Al}_{12} \mathrm{~N}_{12}\right)$ is increased to $\left(8.89 \times 10^{5} \mathrm{au}\right)$ [26]. A related study is performed for $\mathrm{B}_{12} \mathrm{~N}_{12}$ which confirms that alkali metal doping has increased its hyperpolarizability to manifold[43]. In addition, alkali metal atom doped complexes, $\mathrm{Li}+\left(\right.$ calix [4] pyrrole) $\mathrm{M}^{-}$; $[\mathrm{M}=\mathrm{Li}, \mathrm{Na}$, and $\mathrm{K}$ ], have shown remarkable increase in hyperpolarizability value of up to $7.3 \times 10^{3}$ au[44]. Likewise, alkali metal doped aromatic rings (indole, thiophene, and benzene) show enhanced electronic properties and exhibit large hyperpolarizability values from $6.7 \times 10^{3}$ to $9.3 \times 10^{3}$ au[45]. Muhammad et al. have reported that decoration of $\mathrm{Si}_{12} \mathrm{C}_{12}$ with alkali metals shows enhancement in first hyperpolarizability up to $5.7 \times 10^{3}$ au[46]. A remarkable nonlinear optical response of 
$7.9 \times 10^{5}$ au for $\mathrm{K} @ \mathrm{P}_{\text {top }}-\mathrm{B}_{12} \mathrm{P}_{12}$ has been studied by Maria et al. [47]. Literature reveals lot of reports on single and multi-atom doping but no study is found on bi-metal doping of nanocages. There is a need to explore bi-metal doping strategy to design novel NLO materials.

$\mathrm{B}_{12} \mathrm{P}_{12}$ is a refractory semiconducting structure. Boron phosphide has been synthesized by molten nickel or nickel phosphide reactions [48], solid state metathesis reaction[49], sun fluxed assisted synthesis[50] and high temperature reactions of elements[51]. It holds extreme binding affinity for a number of surfaces, making it an excellent contestant for various practical applications[52]. To date, boron phosphide nanocages have been explored by using number of strategies for their applications as NLO materials[53][54], hydrogen storage media[55][56], chemical sensors specifically for $\mathrm{SO}_{2}$ [57] and phenol[58], and as catalytic materials[59]. Doping single alkali metal atoms is a popular and the most used strategy to introduce excess electrons in doped systems. In this study, we are specifically interested to study the considerable impacts of bi-alkali metal atoms doping on $\mathrm{B}_{12} \mathrm{P}_{12}$ nanocage and subsequently its NLO response. All parameters including geometries, NBO analysis, dipole moment, polarizability and hyperpolarizability, NCI and QTAIM analysis are studied to get deep insight of NLO response of bi-alkali metal doped nanocage. Moreover, UV-Vis, IR spectra have been explained to examine the effects of bi-metal doping on the absorption properties of $\mathrm{B}_{12} \mathrm{P}_{12}$. This study will provide a new approach to design highly stable bi-metal doped $\mathrm{B}_{12} \mathrm{P}_{12}$ based NLO materials.

\section{Computational Details}

All calculations in this study were performed using the Gaussian 16 software package[60] and structures have been visualized by using GaussView 5.0[61]. The reported structures in this work are optimized at (Becke's three-parameter hybrid functional (B3) in relation to the gradient corrected correlation functional of Lee-Yang-Parr (LYP) using B3LYP with 6$31 \mathrm{G}(\mathrm{d}, \mathrm{p})$ computational level of theory. True minima for all the structures are characterized by 
frequency calculations at B3LYP/6-31G(d,p) level of theory. To confirm the extent of stability for designed structures, adsorption energies are analyzed by using given equation:

$$
E_{\text {ads }}=E_{\text {complex }}-\left(E_{\text {cage }}+E_{M 2}\right)
$$

In this equation $\mathrm{E}_{\text {complex }}$ is the energy of doped nanocage, $\mathrm{E}_{\text {cage }}$ is the energy of bare $\mathrm{BP}$ nanocage while $\mathrm{E}_{\mathrm{M} 2}$ stands for the sum energy of doped bi-metal atoms only. These energies are zero-point corrected vibrational energies. NBO (natural bond orbital) and infra-red analysis were also executed using the same level of theory.

Polarizability, first hyperpolarizability and dipole moment are

$$
\begin{aligned}
& \alpha_{\circ}=\frac{1}{3}\left(\alpha_{x x}+\alpha_{y y}+\alpha_{y y}\right) \\
& \beta_{\circ}=\left(\beta_{x}^{2}+\beta_{y}^{2}+\beta_{z}^{2}\right)^{\frac{1}{2}}
\end{aligned}
$$

Where,

$$
\begin{aligned}
& \beta_{x}=\beta_{x x x}+\beta_{y y y}+\beta_{z z z} \\
& \beta_{y}=\beta_{y y y}+\beta_{y z z}+\beta_{y x x} \\
& \beta_{z}=\beta_{z z z}+\beta_{z x x}+\beta_{z y y}
\end{aligned}
$$

And dipole moment is

$$
\mu_{\circ}=\left(\mu_{x}^{2}+\mu_{y}^{2}+\mu_{z}^{2}\right)^{\frac{1}{2}}
$$

Polarizability and first hyperpolarizability are calculated at CAM-B3LYP/6-311+G(d) level of theory as the earlier reported data have disclosed this as well-established method for computing hyperpolarizability of inorganic nanocages [62]. Moreover, TD-DFT (time-dependent density functional theory) computations are performed using CAM-B3LYP/6-311+G(d) 
computational level of theory to execute absorption spectra and crucial excited states of all complexes. Partial density of states (PDOS) were generated through MultiWfn software[63].

To get more insights into bonding patterns, QTAIM topological analysis was performed and the corresponding wave functions were produced. The attributes of the bond critical points (BCP) with reference to electron density $(\boldsymbol{\rho})$ and its laplacian $\left(\nabla^{2} \rho\right)$, the potential electron energy density $\left(\mathbf{V}_{(\mathbf{r})}\right)$, Lagragian kinetic energy $\left(\mathbf{G}_{(\mathbf{r})}\right)$, and the total density of electron energy $\left(\mathbf{H}_{(\mathbf{r})}\right)$ were obtained and analyzed.

Noncovalent interaction-reduced density gradient (NCI-RDG) strategy has been employed to identify the nature of bonding interactions between dopants and nanocage. The NCI implication depends on the reduced density gradient (s) and electron density ( $\mathbf{\rho})$. The said relation is as following:

$$
S=\frac{1}{2\left(3 \pi^{2}\right)^{\frac{1}{3}}} \frac{|\nabla \rho|}{\rho^{4 / 3}}
$$

By operating the three parameters along the three foremost axis of maximal variation, the laplacian can be narrated as

$$
\nabla^{2}=\lambda_{1}+\lambda_{2}+\lambda_{3}
$$

NCI isosurfaces are represented by green, red and blue color keys to describe weak Vander Waals forces, destabilizing steric interactions or hydrogen bonding in molecules. Moreover NCI-RDG and AIM analysis were performed using MultiWfn software program in combination with visual molecular dynamic (VMD) software[64]. 


\section{Results and Discussion}

First of all, pristine boron phosphide nanocage and alkali metal atoms were optimized and the computed results are comparable with already reported data[47][53]. Pristine $\mathrm{B}_{12} \mathrm{P}_{12}$ has $C_{2} V$ symmetry. It contains six four-membered rings and eight six-membered rings of B-P bonds. The length of B-P bond is $1.92 \AA$ in four-membered rings and $1.90 \AA$ for six-membered rings. The geometrical and electronic properties of bare nanocage are completely transformed when decorated with alkali metal atoms. A detailed study on bi-alkali metal atoms ( $\mathrm{Li}, \mathrm{Na}, \mathrm{K}$ ) interaction with boron phosphide nanocage is carried out by considering all possible doping positions in a trans-fashion. All designed complexes are optimized to true minima and with all real frequencies. There are total six positions where alkali metals can be decorated at transpositions (above and below the selected place).These positions are the top of boron atom ( $\left.\mathrm{M}_{2} @ \mathrm{~B}\right)$, phosphorus atom $\left(\mathrm{M}_{2} @ \mathrm{P}\right), \mathrm{B}-\mathrm{P}$ bond fused between six-membered ring $\left(\mathrm{M}_{2} @ \mathrm{~b}_{66}\right)$, B-P bond fused between four and six-membered rings ( $\left.\mathrm{M}_{2} @ \mathrm{~b}_{64}\right)$, over the center of sixmembered ring $\left(\mathrm{M}_{2} @ \mathrm{r} 6\right)$, over the center of four membered ring $\left(\mathrm{M}_{2} @ \mathrm{r}_{4}\right)$.We scanned all these possible positions and five structures for Li ( $\left.\mathrm{M}_{2} @ \mathrm{~b}_{64}, \mathrm{M}_{2} @ \mathrm{~b}_{66}, \mathrm{M}_{2} @ \mathrm{r}_{6}, \mathrm{M}_{2} @ \mathrm{~B}, \mathrm{M}_{2} @ \mathrm{P}\right)$, four structures for sodium ( $\left.\mathrm{M}_{2} @ \mathrm{~b}_{66}, \mathrm{M}_{2} @ \mathrm{r}_{6}, \mathrm{M}_{2} @ \mathrm{r}_{4}, \mathrm{M}_{2} @ \mathrm{P}\right)$ and three structures for potassium ( $\left.\mathrm{M}_{2} @ \mathrm{~b}_{64}, \mathrm{M}_{2} @ \mathrm{~b}_{66}, \mathrm{M}_{2} @ \mathrm{r}_{6}\right)$ have been successfully obtained. All the optimized structures are given in Figs. 1 and $\mathrm{S} 1$.

\subsection{Geometrical Parameters}

We have computed interaction distances of decorated alkali metal atoms with the neighboring boron and phosphorus atom. The distance of both alkali metal atoms with neighboring atoms is almost same as can be seen from Table 1. The distance between sodium and boron atoms in structure $\mathrm{Na}_{2} @ \mathrm{P}$ is $4.15 \AA$ than in structure Li $i_{2} @ \mathrm{P}$ that is $3.73 \AA$. Likewise, bond distance in

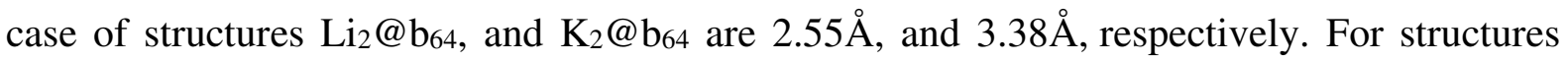
$\left(\mathrm{M}_{2} @ \mathrm{~b}_{66} ; \mathrm{M}=\mathrm{Li}, \mathrm{Na}, \mathrm{K}\right)$, the bond distances with the nearest phosphorus atom are $2.46 \AA$, 
$2.98 \AA$ and $3.38 \AA$, respectively. This increasing trend is due to increasing atomic number of the considered alkali metals. The distances between the metal atoms $\left(\mathrm{M}_{25}\right.$ and $\left.\mathrm{M}_{26}\right)$ and neighboring phosphorus atom are $2.74 \AA$ and $2.99 \AA$ in Na2@ $\mathrm{r}_{4}$. The minimum distances are

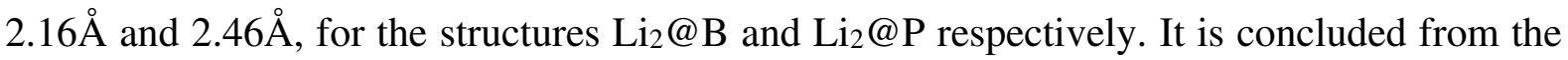
results that internuclear distance from the nearest boron or phosphorus atom for all the complexes increases with the increasing atomic number of alkali metal atoms. All these results are summarized in Table 1.

NBO calculations have been executed for all optimized complexes. Bi-doped alkali metals showed positive NBO charges. These positive charges confirm the transfer of charges toward nanocage. The reason for positive charge on metal atoms lies upon electropositive nature of alkali metals. The results show that both doped metals possess almost same positive charges. Sodium atoms in case of $\mathrm{Na}_{2} @ \mathrm{P}$ carry less positive charge than any other alkali metal atoms i.e. 0.56 for $\mathrm{M}_{25}$ and 0.57 for $\mathrm{M}_{26}$. Each doped metal in complex $\mathrm{Na}_{2} @ \mathrm{r}_{6}$ has 0.91 charge. The amount of charge depends on the type of metal and its orientation on nanocage. In case of Li2@ $b_{66}$, the $\mathrm{M}_{25}$ carries $0.92 \mathrm{NBO}$ charge and $\mathrm{M}_{26}$ carries 0.85 . In case of sodium complexes, the structure $\mathrm{Na}_{2} @ \mathrm{r}_{6}$ has a maximum charge of 0.91 for both metals and for the complex $\mathrm{Na}_{2} @ \mathrm{P}$, the least charge is 0.56 for $\mathrm{M}_{25}$ and 0.57 for $\mathrm{M}_{26}$. On the other hand, the potassium metal in $\mathrm{K}_{2} @ \mathrm{r}_{6}$ has a maximum positive charge of 0.94 . The results reveal that both lithium atoms in structure $\mathrm{Li}_{2} @ \mathrm{P}$ show 0.71 charge. For potassium doped complexes, maximum charge of 0.94 has been observed for both doped metals in structure $\mathrm{K}_{2} @ \mathrm{r} 6$ and the lowest charge of 0.91 for $\mathrm{K}_{2} @ \mathrm{~b}_{64}$ complex. In a nutshell, the positive charges on alkali metals in doped nanocages fluctuate from 0.56 to 0.94 , and confirm transfer of charges from metal atoms to boron phosphide nanocage. All computed NBO charges are given in Table 1.

Dipole moments of all the optimized complexes are given in Table 2. Pristine boron phosphide nanocage has zero dipole moment because of its uniformity. Whereas, for bi-metal doped 
nanocage, dipole moment has increased to some extent due to the increased number of point charges. The results confirm that dipole moment increases for heavier alkali metal atoms. The complex, $\mathrm{K}_{2} @ \mathrm{~b}_{64}$, has highest charge separation than other complexes thus exhibiting highest dipole moment equal to $11.17 \mathrm{D}$ while $\mathrm{Li}_{2} @ \mathrm{~b}_{64}$ has dipole moment of 7.33D. The dipole moment of $\mathrm{Na}_{2} @ \mathrm{r}_{4}$ complex is $0.02 \mathrm{D}$. The dipole moments for $\mathrm{Na}_{2} @ \mathrm{r}_{6}$ and $\mathrm{K}_{2} @ \mathrm{r}_{6}$ complexes is $0.001 \mathrm{D}$ and $0.01 \mathrm{D}$, respectively. Moreover, structure with bi-metallic elements doped on boron site $\left(\mathrm{Li}_{2} @ \mathrm{~B}\right)$ exhibits dipole moment of 3.85D. These results also reveal the high polarity for most of the designed $\mathrm{B}_{12} \mathrm{P}_{12}$ complexes.

Interaction energies of all considered complexes are given in Table 2. All these structures are fully relaxed to true minima. To confirm the stability of complexes the binding energies have been calculated for each complex. Results reveal negative binding energies of complexes which confirm that doping of bi-alkali metal atoms is a feasible process to design optics.

All the binding energies are comparable within the same group of doped nanocages but overall lithium doped nanocages have higher binding energies than sodium and potassium doped complexes. Li2 @ b66, Na2@ b66, and $\mathrm{K}_{2} @ \mathrm{~b}_{66}$ have binding energies (-49.3 kcal/mol, -20.4 kcal/mol and -31.9 kcal/mol), respectively. Li $2 @ \mathrm{r}_{6}, \mathrm{Na}_{2} @ \mathrm{r}_{6}$ and $\mathrm{K}_{2} @ \mathrm{r}_{6}$ have $-43.3 \mathrm{kcal} / \mathrm{mol},-$ $22.6 \mathrm{kcal} / \mathrm{mol}$ and $-34.6 \mathrm{kcal} / \mathrm{mol}$ binding energies, respectively. For $\mathrm{Na}_{2} @ \mathrm{r}_{4}$ complex the interaction energy value is $-18.5 \mathrm{kcal} / \mathrm{mole}$. Meanwhile, complexes $\mathrm{M}_{2} @ \mathrm{~b}_{64}(\mathrm{M}=\mathrm{Li}, \mathrm{K})$ have binding energies of $-43.2 \mathrm{kcal} / \mathrm{mol}$ and $-31.7 \mathrm{kcal} / \mathrm{mol}$, respectively. As concluded from the above discussion, Li2@ @b6 has the highest adsorption energy among all complexes. The complex, Li $2 @ B$, has adsorption energy of -49.3 kcal/mole, while Li ${ }_{2} @ \mathrm{P}$, and $\mathrm{Na}_{2} @ \mathrm{P}$ have adsorption energies of $-22.5 \mathrm{kcal} / \mathrm{mol}$ and $-31.9 \mathrm{kcal} / \mathrm{mol}$, respectively. This shows that the boron site has higher thermodynamic stability than that of phosphorus site. The bi-metal doped complexes have interaction energies twofold higher than single metal doped $\mathrm{B}_{12} \mathrm{P}_{12}$ cage [47]. As in case of Li, single metal doped Li@b66 has adsorption energy of $-21.77 \mathrm{kcal} / \mathrm{mol}$ while 
Li2@ @66 has -49.3kcal/mol energy. Sodium doped complex Na@P has adsorption energy $12.34 \mathrm{kcal} / \mathrm{mol}$ while $\mathrm{Na}_{2} @ \mathrm{P}$ has $-31.9 \mathrm{kcal} / / \mathrm{mol}$ of interaction energy. These some examples confirm bi-metal doped complexes as thermodynamically more stable structures than single metal doped complexes.

\subsection{Electronic Properties}

\section{HOMO-LUMO Analysis}

Boron phosphide $\left(\mathrm{B}_{12} \mathrm{P}_{12}\right)$ is a semiconducting material that has a wide HOMO-LUMO gap of $3.7 \mathrm{eV}$. When doped with alkali metals remarkable reduction in band gap is resulted. All HOMO, LUMO energies and the respective band gaps are given in Table 3 . This reduction in HOMO-LUMO gap is considerable in sodium doped structures i.e. $H$ - $L$ gaps for $\mathrm{Na}_{2} @ \mathrm{r}_{4}$, $\mathrm{Na}_{2} @ \mathrm{r}_{6}$ and $\mathrm{Na}_{2} @ \mathrm{r}_{66}$ complexes are $0.95 \mathrm{eV}, 1.58 \mathrm{eV}$ and $1.16 \mathrm{eV}$, respectively. The $H$ - $L$ gap of $\mathrm{Na}_{2} @ \mathrm{P}$ complex is $0.56 \mathrm{eV} . H-L$ gap is significantly decreased for the structures Li2 @ $\mathrm{b}_{64}$ $(1.53 \mathrm{eV})$ and $\mathrm{Li}_{2} @ \mathrm{r}_{6}(1.58 \mathrm{eV})$, respectively. These results (Table 3) predict that more than 50\% of $H$ - $L$ gap has been reduced in bi-metal doped nanocages. The $H-L$ gaps in potassium doped structures range from $1.17 \mathrm{eV}$ to $1.09 \mathrm{eV}$. It is illustrated that the energy of HOMO has somewhat increased than LUMO. This may be due to the reason of interaction between metal atoms and nanocage and the excess electrons of alkali metals are transferred towards the nanocage. This phenomenon increases the energy of HOMO and reduces energy gap. The lowest HOMO-LUMO gap has been observed for the structure $\mathrm{Na} 2 @ \mathrm{P}(0.56 \mathrm{eV})$.

The charge transfer from metals have influenced the fermi levels of the doped systems. The transfer of charge from metal to nanocage has been confirmed by NBO analysis. The positive charges on metal atoms indicate transfer of electrons from alkali metal atoms to $\mathrm{B}_{12} \mathrm{P}_{12}$ nanocage thus resulting in formation of new energy HOMOs. This transfer of electrons and new high energy HOMO have contributed towards increased fermi levels. Fermi levels for all 
doped complexes have increased and are given in Table 3.The complex $\mathrm{K}_{2} @ \mathrm{r}_{6}$ with the highest charge transfer shows the highest fermi level value of $-2.37 \mathrm{eV}$. New fermi levels for $\mathrm{Li}_{2} @ \mathrm{~b}_{64}$ and $\mathrm{K}_{2} @ \mathrm{~b}_{64}$ have been originated at $-3.29 \mathrm{eV}$ and $-2.42 \mathrm{eV}$, respectively as greater charge transfer of $|0.91|$ from each $\mathrm{K}$ atom has been observed for the later complex. On the other hand, $\mathrm{Li}_{2} @ \mathrm{P}$ shows the higher value $(-2.83 \mathrm{eV})$ of fermi level than $\mathrm{Na}_{2} @ \mathrm{P}(-2.90 \mathrm{eV})$ as the NBO charge transfers are $|0.71|$ and $|0.56|$, respectively. For the doped position of $\mathrm{b}_{66}$, the fermi levels follow the order of $\mathbf{L i}_{\mathbf{2}} @ \mathbf{b}_{\mathbf{6 6}}<\mathbf{N} \mathbf{a}_{\mathbf{2}} @ \mathbf{b}_{\mathbf{6 6}}<\mathbf{K}_{\mathbf{2}} @ \mathbf{b}_{\mathbf{6 6}}$ as the maximum average NBO charge transfer is observed for $\mathbf{K}_{\mathbf{2}} @ \mathbf{b}_{\mathbf{6 6}}$ and minimum for $\mathbf{L i}_{\mathbf{2}} @ \mathbf{b}_{\mathbf{6 6}}$.These results predict that doping of bi-alkali metals has substantially decreased HOMO-LUMO gap, hence making them excellent materials to use in many conducting and optoelectronic devices. The densities of the HOMO and LUMO orbitals are presented in Fig. 2. To further elaborate the effect of bi-metal doping, TDOS (total density of states) and PDOS (partial density of states) for pristine and doped cages are plotted. By comparing with bare nanocage, it is evident that a new high energy HOMO has appeared between the original HOMO and LUMO of $\mathrm{B}_{12} \mathrm{P}_{12}$ nanocage that has remarkably decreased the $H O M O-L U M O$ gap. It is demonstrated from PDOS spectra that doped alkali metals are taking part in the formation of new HOMOs by transferring charge towards nanocage. These graphs clearly show that new HOMO is lying on alkali metals and nanocage. HOMO and LUMO structures and TDOS and PDOS of complexes with lowest HOMO-LUMO gap for each dopant are shown in Figs.2 and 3, respectively (see supporting information Fig S2 and S3 for rest of the structures).

\subsection{Polarizability and First Hyperpolarizability Analysis}

It has been reported that the nonlinear optical response improves efficiently when excess electrons are introduced into a system. These electrons create new high energy HOMO and enhance the polarizability and first hyperpolarizability of systems. Polarizability, first 
hyperpolarizability, and crucial excited state composition of all designed complexes are given in Table 4. For pristine boron phosphide nanocage, the polarizability value is 402.24 au. It is observed that polarizability values have increased after decorating bi-alkali metal atoms on boron phosphide nanocage. The largest polarizability is 1300.37 au for $\mathrm{Na} 2 @ \mathrm{P}$. The potassium doped structures show increased polarizabilities values ranging from 602.45 au to 634.69 au. The polarizability value for $\mathrm{Li}_{2} @ \mathrm{~B}$ complex is 1016.2 au while for the sodium doped structures the values of polarizability start from 595.29 au to the highest value of $1300.37 \mathrm{au}$.

Pristine boron phosphide nanocage has zero hyperpolarizability due to symmetry of the cage. We calculated the first hyperpolarizability of bi-metal doped boron phosphide nanocage and results reveal that hyperpolarizability of doped nanocage has increased as compared to bare boron phosphide nanocage due to change in symmetry of nano cluster. The highest $\beta_{o}$ value of $4.06 \times 10^{4} \mathrm{au}$ is for the structure $\mathrm{K}_{2} @ \mathrm{~b}_{64}$, while for the structures $\mathrm{Li}_{2} @ \mathrm{~b}_{64}$, and $\mathrm{Li}_{2} @ \mathrm{~b}_{66}$ hyperpolarizability values are $1.4 \times 10^{4}$ au is $1.4 \times 10^{3}$ au respectively. For structures $\mathrm{Na}_{2} @ \mathrm{~b}_{66}$ and $\mathrm{Na}_{2} @ \mathrm{r}_{4}$, the hyperpolarizability values are $6.1 \times 10^{2}$ au and $3.2 \times 10^{2} \mathrm{au}$, respectively. The hyperpolarizability values for the structures with metals doped on boron atom Li2@B is $1.64 \times 10^{3} \mathrm{au}$. Hyperpolarizability has an inverse relation with HOMO-LUMO gap but results reveal that this trend is not followed by some complexes.

\subsection{UV-visible Exploration}

To examine UV-visible spectral properties of the bare and doped nanocage, TD-DFT calculations have been performed. The results obtained by these calculations are summarized in Table 5.

The UV-visible analysis reveals that all doped complexes show a bathochromic shift as compared to bare $\mathrm{B}_{12} \mathrm{P}_{12}$ nanocage. The UV-visible spectra of doped nanocages show absorbance from visible to the infrared region while bare nanocage showed absorbance peak in ultraviolet region. For structures $\mathrm{M}_{2} @ \mathrm{~b}_{64}(\mathrm{M}=\mathrm{Li}, \mathrm{K})$, the maximum absorptions are at 
$984.24 \mathrm{~nm}$ and $1122.69 \mathrm{~nm}$, respectively. For structure $\mathrm{Li}_{2} @ \mathrm{~b}_{66}$ the maximum absorption is at $532.46 \mathrm{~nm}$ which then increases to $1384.55 \mathrm{~nm}$ for $\mathrm{Na}_{2} @ \mathrm{~b}_{66}$ and again decreases to 1272.30 nm for $\mathrm{K}_{2} @ \mathrm{~b} 66$. For position $\mathrm{M}_{2} @ \mathrm{r}_{6}$ the absorption wavelength follows an increasing trend. The absorbance values for $\mathrm{Li}_{2} @ \mathrm{r}_{6}$ is $710.21 \mathrm{~nm}$ that slightly increases to $712.37 \mathrm{~nm}$ for $\mathrm{Na} 2 @ \mathrm{r} 6$ and then 720.61 nm for $\mathrm{K}_{2} @ \mathrm{r}_{6}$. The maximum absorbance of $1980.50 \mathrm{~nm}$ is shown by $\mathrm{Na}_{2} @ \mathrm{P}$ due to the smallest HOMO-LUMO gap. All the UV-visible graphs are shown in Fig. 4.

\subsection{FTIR Analysis}

Pristine boron phosphide nanocage and doped complexes are studied to assess changes in its infra-red spectral properties upon doping. The IR spectra are shown in the Fig. 5. From previous studies, it is evident that doping of alkali metal atom reduces the vibrational frequency of host nanocage [52]. Boron phosphide nanocage has a vibrational frequencies at $761.4 \mathrm{~cm}^{-1}$ and at $894 \mathrm{~cm}^{-1}$. Upon doping bi-metal atoms, these vibration frequencies decrease to a greater extent as compared to reported data. They have moved to $295 \mathrm{~cm}^{-1}$ and $253 \mathrm{~cm}^{-1}$ for $\mathrm{K}_{2} @ \mathrm{~b}_{64}$ complex. The stretching vibration for $\mathrm{K}_{2} @ \mathrm{~b}_{66}$ decreases to $287 \mathrm{~cm}^{-1}$ and $178 \mathrm{~cm}^{-1}$. For Li2@ $\mathrm{b}_{64}$ the vibration frequency decreases to $871 \mathrm{~cm}^{-1}$ and $732 \mathrm{~cm}^{-1}$. This decrease in vibrational frequencies can be justified due to distortion in nanocage that makes boron phosphide bonding weaker in doped complexes. Higher alkali metals cause more distortion in systems, so vibrational frequencies of complexes decrease accordingly.

\section{NCI-RDG Analysis:}

The noncovalent interaction analysis is capable of differentiating the regions of hydrogen bonds, repulsive steric interactions and van der Waals interactions[65][66]. Basically, this analysis was introduced for better understanding of types and nature of intermolecular bonding interactions.

The 3D NCI images for some prominent doped complexes are shown in Fig.6 while rest of isosurfaces are added in supporting information (Fig.S4). On 3D NCI images (isosurfaces), red 
color represents steric repulsion, while yellow and green patches signifies van der Waals interactions and blue patches denote strong attractive bonding interactions. In Fig.6, isosurfaces of complexes reveal steric repulsion in between the atoms of nanocage (B\&P) because red patches in cage are clearly visible. In case of lithium doped complexes, each complex shows van der Waal interactions (green spots) except $\mathrm{Li}_{2} @_{64}$ and Li $2 @ \mathrm{P}$ as these complexes show covalent bond interactions (blue patches). While complexes $\mathrm{Na}_{2} @ \mathrm{r}_{6}, \mathrm{Na}_{2} @ \mathrm{r}_{4}$ and potassium doped complexes show weak van der Waal interaction (green patches) and $\mathrm{Na}_{2} @ \mathrm{P}$ and $\mathrm{Na}_{2} @ \mathrm{~b}_{66}$ show blue patches that clearly indicate strong covalent interaction.

The NCI analysis is composed of graphical representation of $2 \mathrm{D}$ reduced density gradient (RDG) and 3D isosurfaces[67]. The NCI graphs are evoked with the plots of RDG S against $\left(\operatorname{sign} \lambda_{2}\right) \rho$. The term $\left(\operatorname{sign} \lambda_{2}\right) \rho$ represents the electron density into sign of second Hessian eigenvalue $\lambda_{2}$ and is an important factor as its values anticipate the nature of bonding interactions. For attractive and repulsive interactions, the values should be $\left(\operatorname{sign} \lambda_{2}\right) \rho<0$ and $\left(\operatorname{sign} \lambda_{2}\right) \rho>0$, respectively. NCI plots for $\mathrm{B}_{12} \mathrm{P}_{12}$ complexes are given in Fig.6 along with NCI images. In NCI graphs, dispersion attractions appear at $\rho<0.01$ au. (at low density values) while strong attractive bonding interaction spikes occur at $\rho>0.01$ au. (at higher density values). For bi-metal doped complexes with green patches in isosurfaces, high density green peaks at -0.01 to -0.03 au. represent that van der Waal interactions are the key feature of alkali metal adsorption. While high density blue spikes for some lithium and sodium doped structures clearly indicate strong covalent bond interactions and support bonding information obtained from NCI isosurfaces.

\section{QTAIM Analysis}

Quantum theory of atoms in molecule (QTAIM) analysis is a robust tool to examine the type and nature of bonding relationships at bonding critical points (BCPs) of inter or intra-molecular interactions. QTAIM variables of at BCPs of all complexes generated between alkali metals 
and nanocage are depicted in Table 6. The topological investigation of electron density reveals the occurrence of one or more BCPs in between the doped metals and nanocage. The strength of bond is described by the electron density $(\rho)$; larger the value of electron density, stronger will be the bonding interaction. The values of electron density are in range of 0.1059-0.2395 au. The total electron energy density $(\mathrm{Hr})$ and Laplacian of electron density $\left(\nabla^{2} \rho\right)$ are important to ascertain the strength of bonds. The bonding interactions are of covalent type when $\left(\nabla^{2} \rho<\right.$ 0 ) and $\mathrm{Hr}<0$; while in terms of weak bonding (electrostatic), the values are: $\left(\nabla^{2} \rho>0\right)$ and $\mathrm{Hr}$ $<0$.

In case of average strength of $\left(\nabla^{2} \rho\right)>0$ and $\mathrm{Hr}<0$, a partial covalent bond is established. In addition to this a ratio $-\mathrm{Gr} / \mathrm{Vr}>1$ specify non covalent bonding and $-\mathrm{Gr} / \mathrm{Vr}<1$ depicts covalent interactions. In case of $\mathrm{B}_{12} \mathrm{P}_{12}$ decorated with bi-alkali metals parameters $\nabla^{2} \rho>0$ and the ratio $-\mathrm{Gr} / \mathrm{Vr}$ is greater than 1 for all examined complexes thus revealing noncovalent bonding as a major code of adsorption.

\section{Conclusion}

In this study, a new strategy of doping bi-alkali metal atoms has been proposed to increase stability and opto-electronic characteristics of $\mathrm{B}_{12} \mathrm{P}_{12}$ nanocage. Adsorption energies have been calculated to check the feasibility and strength of the doped nanocages. Our results reveal that adsorption energies for bi-alkali metal doped nanocages are almost twofold than the corresponding single metal doped nanocages reported earlier and confirm these structures thermodynamically more stable. Li ${ }_{2} @ \mathrm{~b}_{66}$ shows the highest adsorption energy $(-49.3$ kcal/mole) while Na2@P has the lowest adsorption energy $(-12.4 \mathrm{kcal} / \mathrm{mole}) . \mathrm{NBO}$ analysis indicates the charge transfer from doped metals to nanocage thus creating a new HOMO in boron phosphide cage. Certainly, this strategy serves as an advantage to resolve the high H-L gap of $\mathrm{B}_{12} \mathrm{P}_{12}$. In case of hyperpolarizability, $\mathrm{K}_{2} @ \mathrm{~b}_{64}$ shows maximum hyperpolarizability with 
value of $4.06 \times 10^{4}$ au. Doping of bi-metal has remarkably altered the geometrical and electronic properties of nanocage. HOMO-LUMO gap is reduced to half while hyperpolarizability values have also increased to manifold. NCI and QTAIM analysis reveal noncovalent bonding interaction as a major mode of adsorption between cage and dopants. This study introduces a novel scenario of bi-metal doping for the fabrication of NLO materials.

\section{Declaration of Competing Interest}

The authors declare no competing interest.

\section{Acknowledgments}

This project was financially supported by the Higher Education Commission, Pakistan under HEC-NRPU project (7853). 


\section{References}

1. S. Suresh and D. Arivuoli, 30, 243 (2016).

2. C. G. Liu, W. Guan, P. Song, L. K. Yan, and Z. M. Su, Inorg. Chem. 48, 6548 (2009).

3. E. Shakerzadeh, Z. Biglari, and E. Tahmasebi, Chem. Phys. Lett. 654, 76 (2016).

4. F. Ullah, N. Kosar, M. N. Arshad, M. A. Gilani, K. Ayub, and T. Mahmood, Opt. Laser Technol. 122, 105855 (2020).

5. A. S. Rad and K. Ayub, J. Alloys Compd. 678, 317 (2016).

6. S. S. Varghese, S. Lonkar, K. K. Singh, S. Swaminathan, and A. Abdala, Sensors Actuators, B Chem. 218, 160 (2015).

7. B. Clough, J. Dai, and X. C. Zhang, Mater. Today 15, 50 (2012).

8. E. Shakerzadeh, E. Khodayar, and S. Noorizadeh, Comput. Mater. Sci. 118, 155 (2016).

9. R. D. Peterson, B. T. Cunningham, and J. E. Andrade, Biosens. Bioelectron. 56, 320 (2014).

10. N. Coustel, B. Coq, V. Brotons, P. S. Kumbhar, R. Dutartre, P. Geneste, J. M. Planeix, P. Bernier, and P. M. Ajayan, J. Am. Chem. Soc. 116, 7935 (1994).

11. A. Bachtold, P. Hadley, T. Nakanishi, and C. Dekker, Science (80-. ). 294, 1317 (2001).

12. S. Achelle, C. Baudequin, and N. Plé, Dye. Pigment. 98, 575 (2013).

13. L. R. Dalton, P. A. Sullivan, and D. H. Bale, Chem. Rev. 110, 25 (2010).

14. C. H. Hsieh, L. J. Chou, G. R. Lin, Y. Bando, and D. Golberg, Nano Lett. 8, 3081 (2008).

15. S. Muhammad, J. Mol. Graph. Model. 59, 14 (2015).

16. Y. Wang and L. T. Cheng, J. Phys. Chem. 96, 1530 (1992).

17. M. Schulz, S. Tretiak, V. Chernyak, and S. Mukamel, J. Am. Chem. Soc. 122, 452 (2000).

18. E. M. Y. Lee, A. J. Mork, A. P. Willard, and W. A. Tisdale, J. Chem. Phys. 147, (2017).

19. Q. Li, G. Zou, C. Lin, and N. Ye, New J. Chem. 40, 2243 (2016).

20. L. Bai, S. Qiao, H. Li, Y. Fang, Y. Yang, H. Huang, Y. Liu, Y. Song, and Z. Kang, RSC Adv. 6, 95476 (2016)

21. F. Ullah, N. Kosar, M. N. Arshad, M. A. Gilani, K. Ayub, and T. Mahmood, Opt. Laser Technol. 122, 105855 (2020).

22. R. Bhuvaneswari, J. P. Maria, V. Nagarajan, and R. Chandiramouli, Comput. Theor. Chem. 
$112751(2020)$.

23. S. Mendiratta, C. H. Lee, M. Usman, and K. L. Lu, Sci. Technol. Adv. Mater. 16, 54204 (2015).

24. R. N. Grimes, Mol. Cryst. Liq. Cryst. Sci. Technol. Sect. A Mol. Cryst. Liq. Cryst. 342, 7 (2000).

25. N. Wazzan and Z. Safi, J. Mol. Struct. 1143, 397 (2017).

26. M. Niu, G. Yu, G. Yang, W. Chen, X. Zhao, and X. Huang, Inorg. Chem. 53, 349 (2014).

27. T. Kato and K. Sugawara, ACS Omega 4, 14714 (2019).

28. H. Sonomura and T. Miyauchi, Japanese J. Appl. Physics, Part 1 Regul. Pap. Short Notes Rev.

Pap. 8, 1263 (1969).

29. H. Anaraki-Ardakani, Phys. Lett. Sect. A Gen. At. Solid State Phys. 381, 1041 (2017).

30. D. L. Strout, J. Phys. Chem. A 104, 3364 (2000).

31. M. A. Gilani, S. Tabassum, U. Gul, T. Mahmood, A. I. Alharthi, M. A. Alotaibi, M. Geesi, R. Sheikh, and K. Ayub, Appl. Phys. A Mater. Sci. Process. 124, 0 (2018).

32. J. Badan, R. Hierle, A. Perigaud, and J. Zyss, ACS Symp. Ser. 81 (1983).

33. G. S. He, J. Zhu, A. Baev, M. Samoć, D. L. Frattarelli, N. Watanabe, A. Facchetti, H. Ågren, T. J. Marks, and P. N. Prasad, J. Am. Chem. Soc. 133, 6675 (2011).

34. I. D. L. Albert, T. J. Marks, and M. A. Ratner, J. Phys. Chem. 100, 9714 (1996).

35. Y. Y. Li, P. F. Liu, H. Lin, M. T. Wang, and L. Chen, Inorg. Chem. Front. 3, 952 (2016).

36. S. Muhammad, A. G. Al-Sehemi, Z. Su, H. Xu, A. Irfan, and A. R. Chaudhry, J. Mol. Graph. Model. 72, 58 (2017).

37. S. Muhammad, M. Nakano, A. G. Al-Sehemi, Y. Kitagawa, A. Irfan, A. R. Chaudhry, R. Kishi, S. Ito, K. Yoneda, and K. Fukuda, Nanoscale 8, 17998 (2016).

38. W. Chen, Z. R. Li, D. Wu, R. Y. Li, and C. C. Sun, J. Phys. Chem. B 109, 601 (2005).

39. Z. J. Li, F. F. Wang, Z. R. Li, H. L. Xu, X. R. Huang, D. Wu, W. Chen, G. T. Yu, F. L. Gu, and Y. Aoki, Phys. Chem. Chem. Phys. 11, 402 (2009).

40. R. Razavi and M. Najafi, J. Solid State Electrochem. 23, 759 (2019).

41. N. Hou, Y. Y. Wu, and J. Y. Liu, Int. J. Quantum Chem. 116, 1296 (2016).

42. S. Muhammad, H. Xu, Y. Liao, Y. Kan, and Z. Su, J. Am. Chem. Soc. 131, 11833 (2009).

43. Maria, J. Iqbal, and K. Ayub, J. Alloys Compd. 687, 976 (2016). 
44. W. Chen, Z. R. Li, D. Wu, Y. Li, C. C. Sun, F. L. Gu, and Y. Aoki, J. Am. Chem. Soc. 128, 1072 (2006).

45. A. Allouche, J. Comput. Chem. 32, 174 (2012).

46. M. Solimannejad, R. Rahimi, and S. Kamalinahad, J. Inorg. Organomet. Polym. Mater. 27, 1234 (2017).

47. S. Munsif, Maria, S. Khan, A. Ali, M. A. Gilani, J. Iqbal, R. Ludwig, and K. Ayub, J. Mol. Liq. 271, 51 (2018).

48. T. L. Chu, J. M. Jackson, and R. K. Smeltzer, J. Electrochem. Soc. 120, 802 (1973).

49. R. E. Treece, E. G. Gillan, and R. B. Kaner, Comments Inorg. Chem. 16, 313 (1995).

50. K. Woo, K. Lee, and K. Kovnir, Mater. Res. Express 3, 1 (2016).

51. V. A. Mukhanov, P. S. Sokolov, Y. Le Godec, and V. L. Solozhenko, J. Superhard Mater. 35, 415 (2013).

52. Maria, J. Iqbal, R. Ludwig, and K. Ayub, Mater. Res. Bull. 92, 113 (2017).

53. F. Ullah, N. Kosar, K. Ayub, M. A. Gilani, and T. Mahmood, New J. Chem. 43, 5727 (2019).

54. S. Irshad, F. Ullah, S. Khan, R. Ludwig, T. Mahmood, and K. Ayub, Opt. Laser Technol. 134, $106570(2021)$.

55. J. Beheshtian, M. Kamfiroozi, Z. Bagheri, and A. Ahmadi, Comput. Mater. Sci. 54, 115 (2012).

56. N. Khossossi, Y. Benhouria, S. R. Naqvi, P. K. Panda, I. Essaoudi, A. Ainane, and R. Ahuja, Sustain. Energy Fuels 4, 4538 (2020).

57. S. Hussain, S. A. S. Chatha, A. I. Hussain, R. Hussain, M. Y. Mehboob, S. Muhammad, Z. Ahmad, and K. Ayub, J. Chem. 2020, (2020).

58. A. Soltani, M. T. Baei, M. R. Taghartapeh, E. T. Lemeski, and S. Shojaee, Struct. Chem. 26, 685 (2015).

59. Y. Wang, W. Gong, P. Zuo, L. Kang, and G. Yin, Catal. Letters 150, 544 (2020).

60. M. J. . T. Frisch G. W.; Schlegel, H. B.; Scuseria, G. E.; Robb, M. A.; Cheeseman, J. R.; Scalmani, G.; Barone, V.; Petersson, G. A.; Nakatsuji, H.; Li, X.; Caricato, M.; Marenich, A. V.;

Bloino, J.; Janesko, B. G.; Gomperts, R.; Mennucci, B.; Hratch, D. J., Gaussian, Inc., Wallingford, CT (2016).

61. R. Dennington, T. Keith, and J. Millam, Semichem Inc., Shawnee Mission. KS (2009). 
62. F. Ullah, N. Kosar, A. Ali, Maria, T. Mahmood, and K. Ayub, Phys. E Low-Dimensional Syst. Nanostructures 118, (2020).

63. T. Lu and F. Chen, J. Comput. Chem. 33, 580 (2012).

64. W. Humphrey, A. Dalke, and K. Schulten, J. Mol. Graph. 14, 33 (1996).

65. C. L. Firme, N. K. V. Monteiro, and S. R. B. Silva, Comput. Theor. Chem. 1111, 40 (2017).

66. C. Lefebvre, G. Rubez, H. Khartabil, J. C. Boisson, J. Contreras-García, and E. Hénon, Phys. Chem. Chem. Phys. 19, 17928 (2017).

67. M. Yar, M. A. Hashmi, and K. Ayub, RSC Adv. 10, 31997 (2020). 

Figures

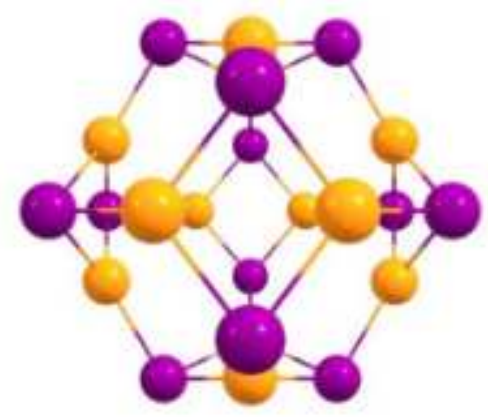

$$
\mathrm{B}_{12} \mathrm{P}_{12}
$$

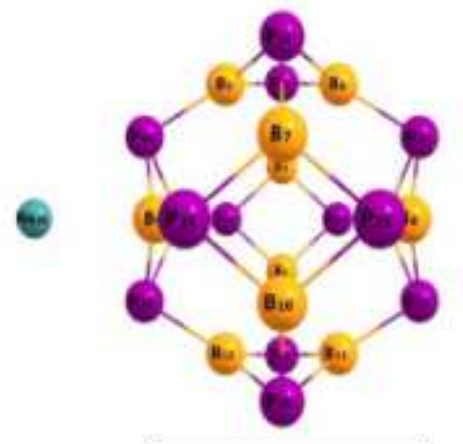

$\mathrm{Na}_{2} @ \mathrm{r}_{4}$

E.

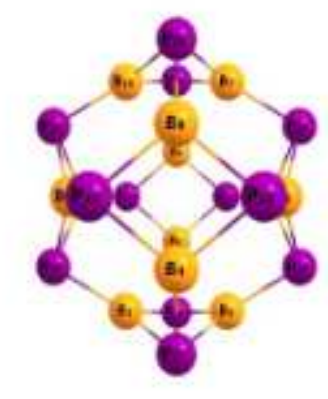

$\mathbf{K}_{2} @ \mathbf{b}_{64}$

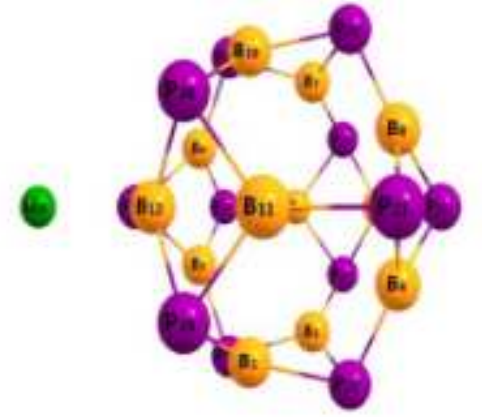

$\mathrm{Li}_{2} @ \mathbf{P}$

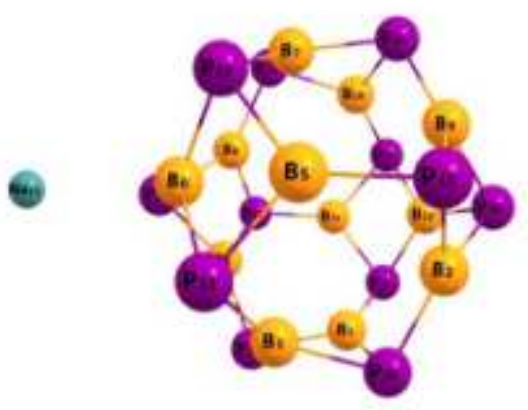

6

$$
\mathrm{Na}_{2} @ \mathrm{P}
$$

(2)

Figure 1

Optimized geometries of pure B12P12 and bi-alkali metal doped boron phosphide complexes 


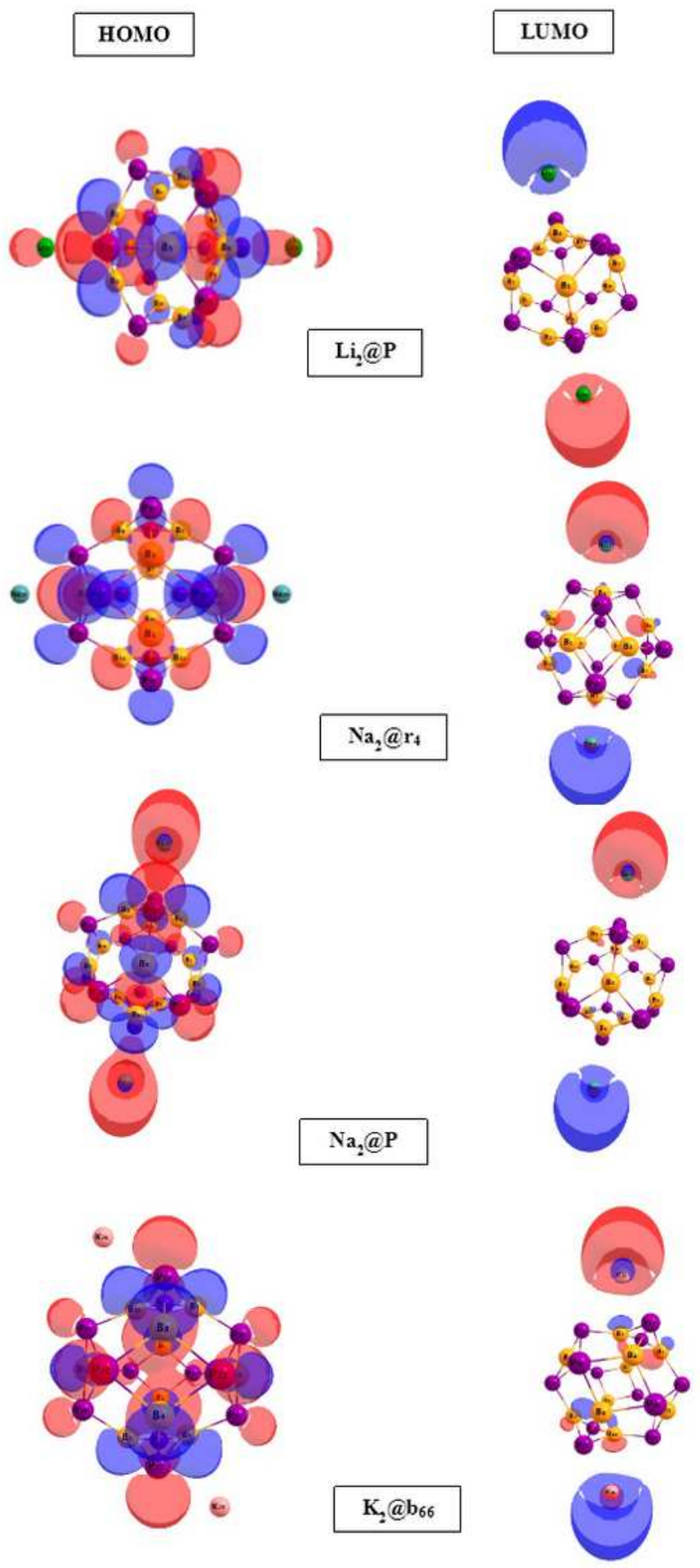

Figure 2

HOMO-LUMO structure of bi-metal doped boron phosphide complexes 

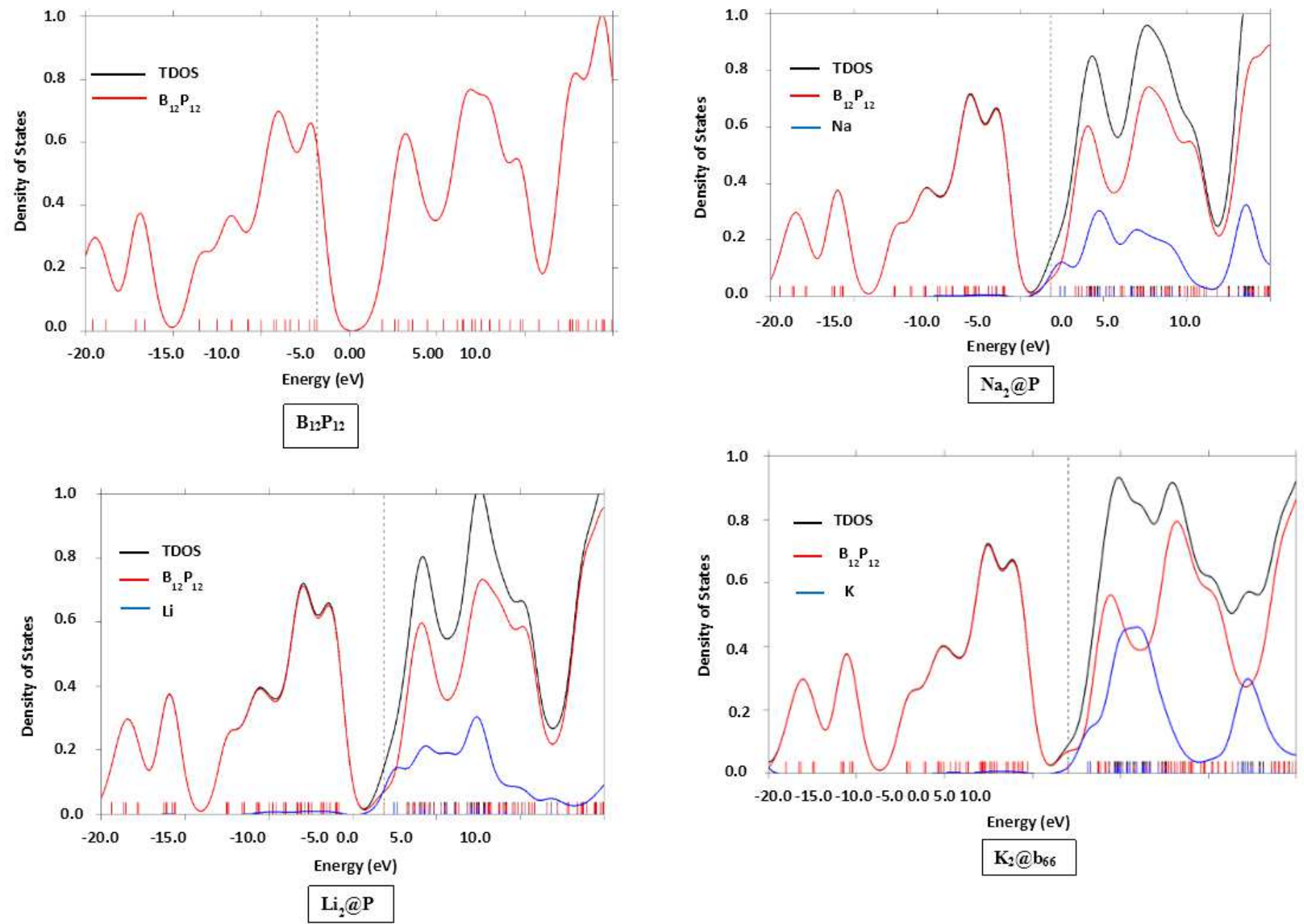

Figure 3

TDOS and PDOS of pristine nanocage and bi-alkali metal doped complexes 

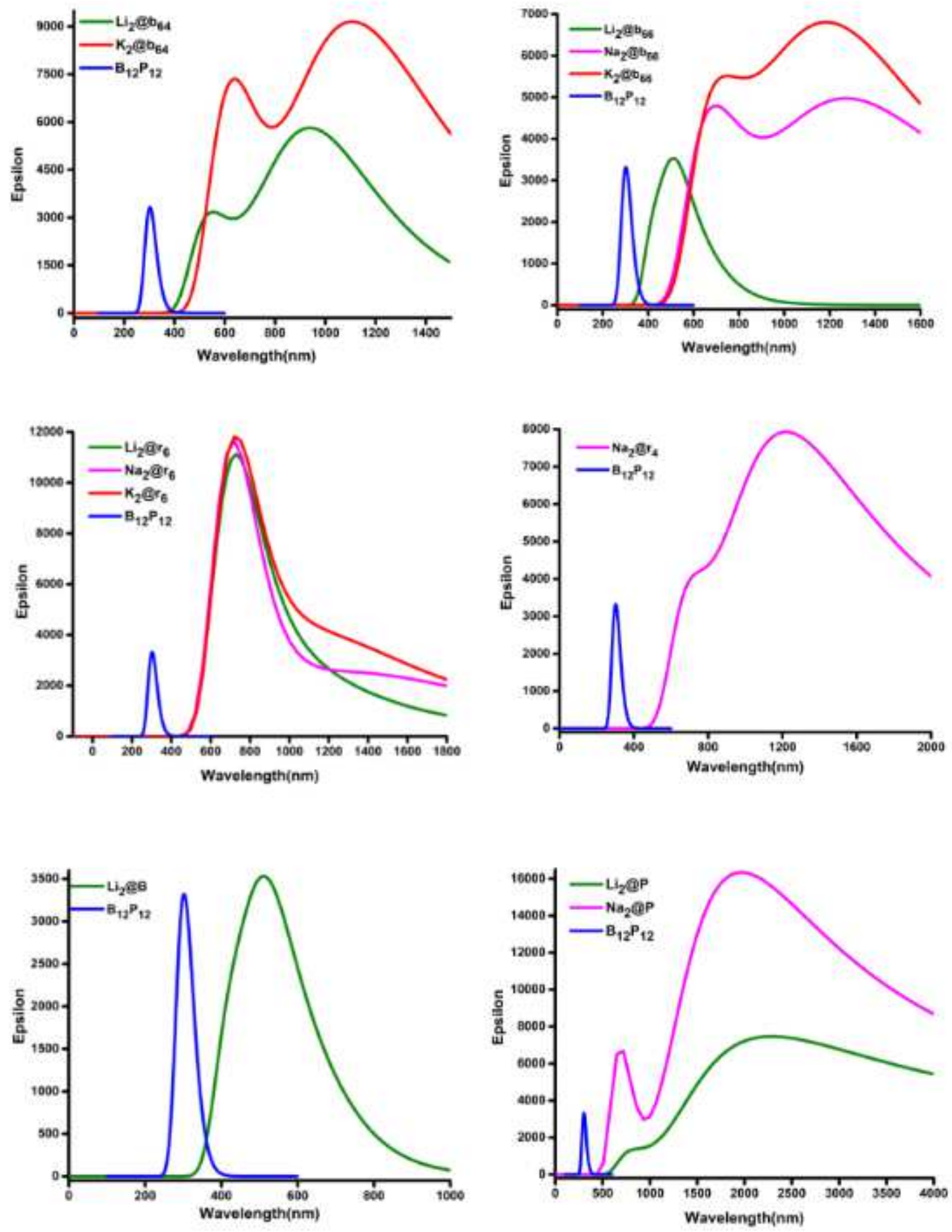

Figure 4

UV-visible spectra of B12P12 and doped complexes 

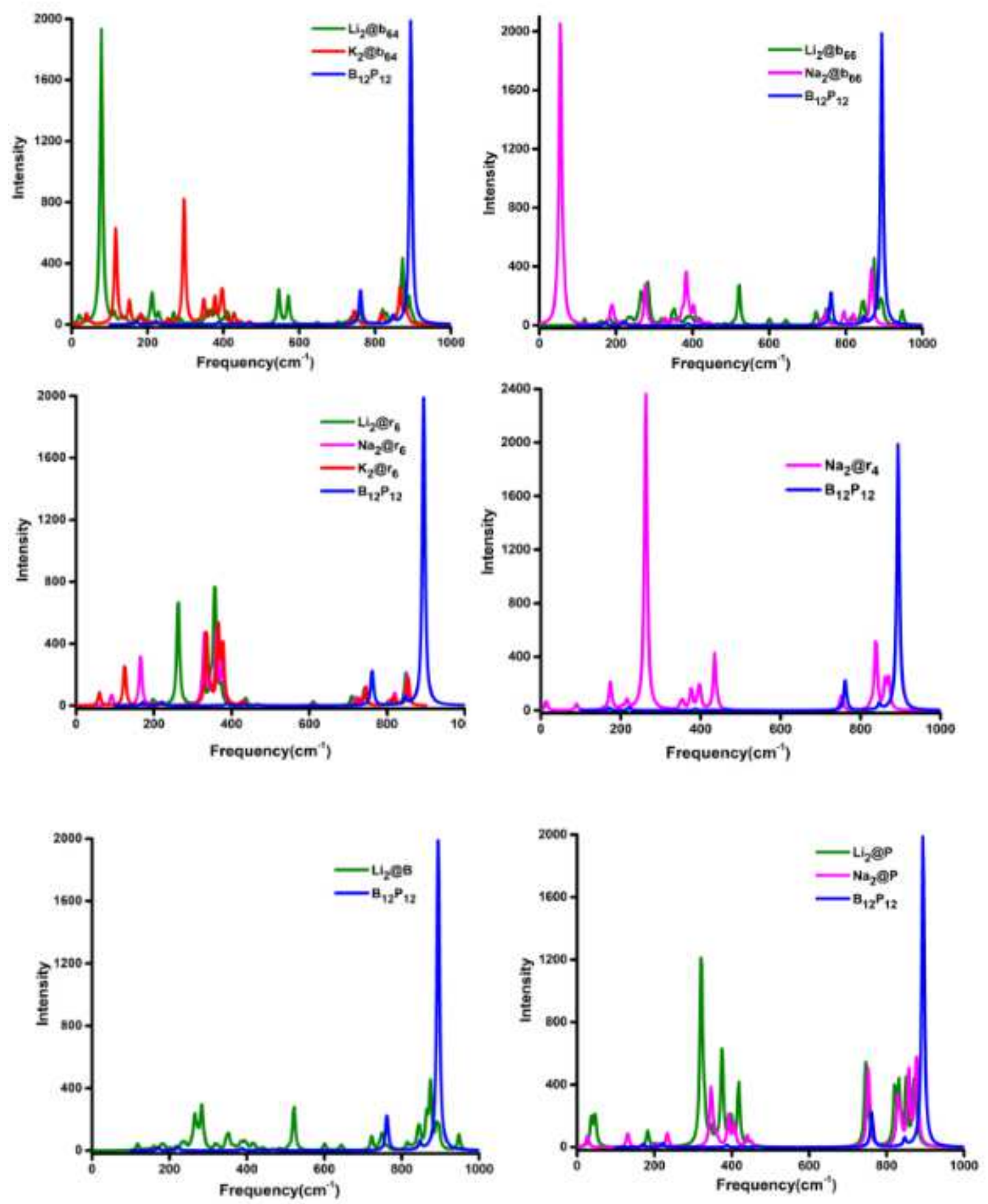

Figure 5

IR analysis of bare boron phosphide and bi-alkali metal doped nanocages 

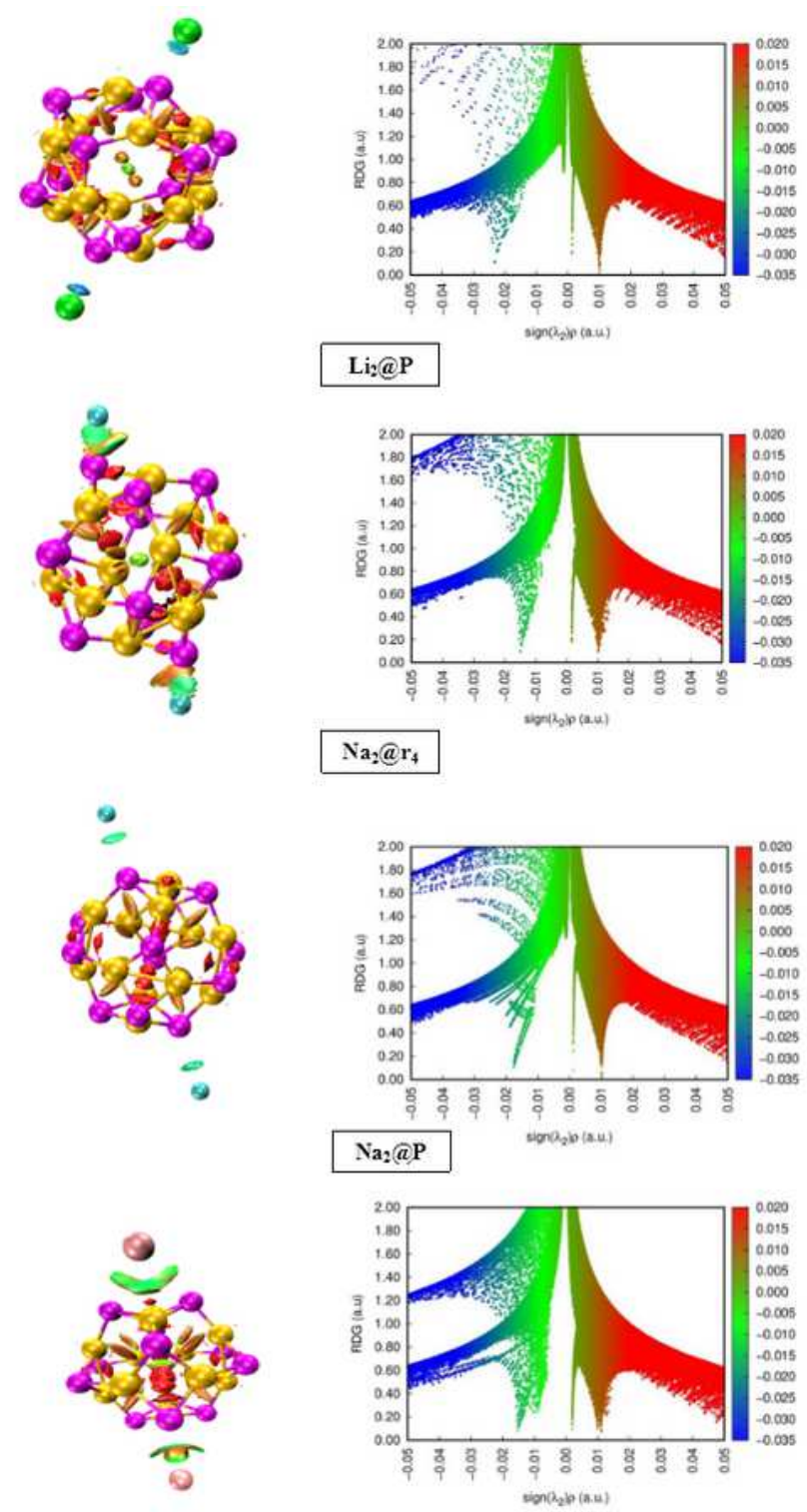

$\mathbf{K}_{2} @ \mathbf{b}_{64}$
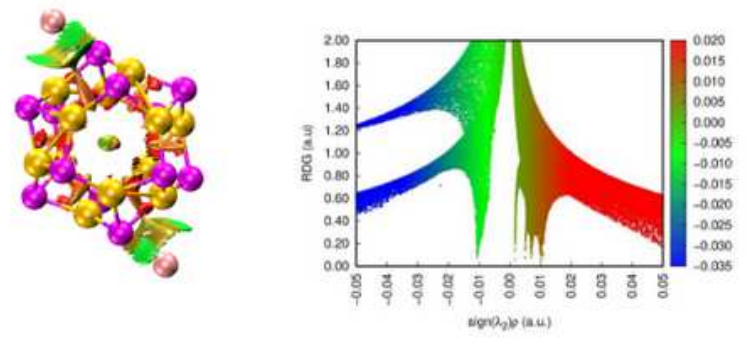

$\mathrm{K}_{2} @ \mathrm{r}_{6}$

\section{Figure 6}

3D NCl images along with 2D NCl plots of bi-alkali metal doped B12P12 complexes. 

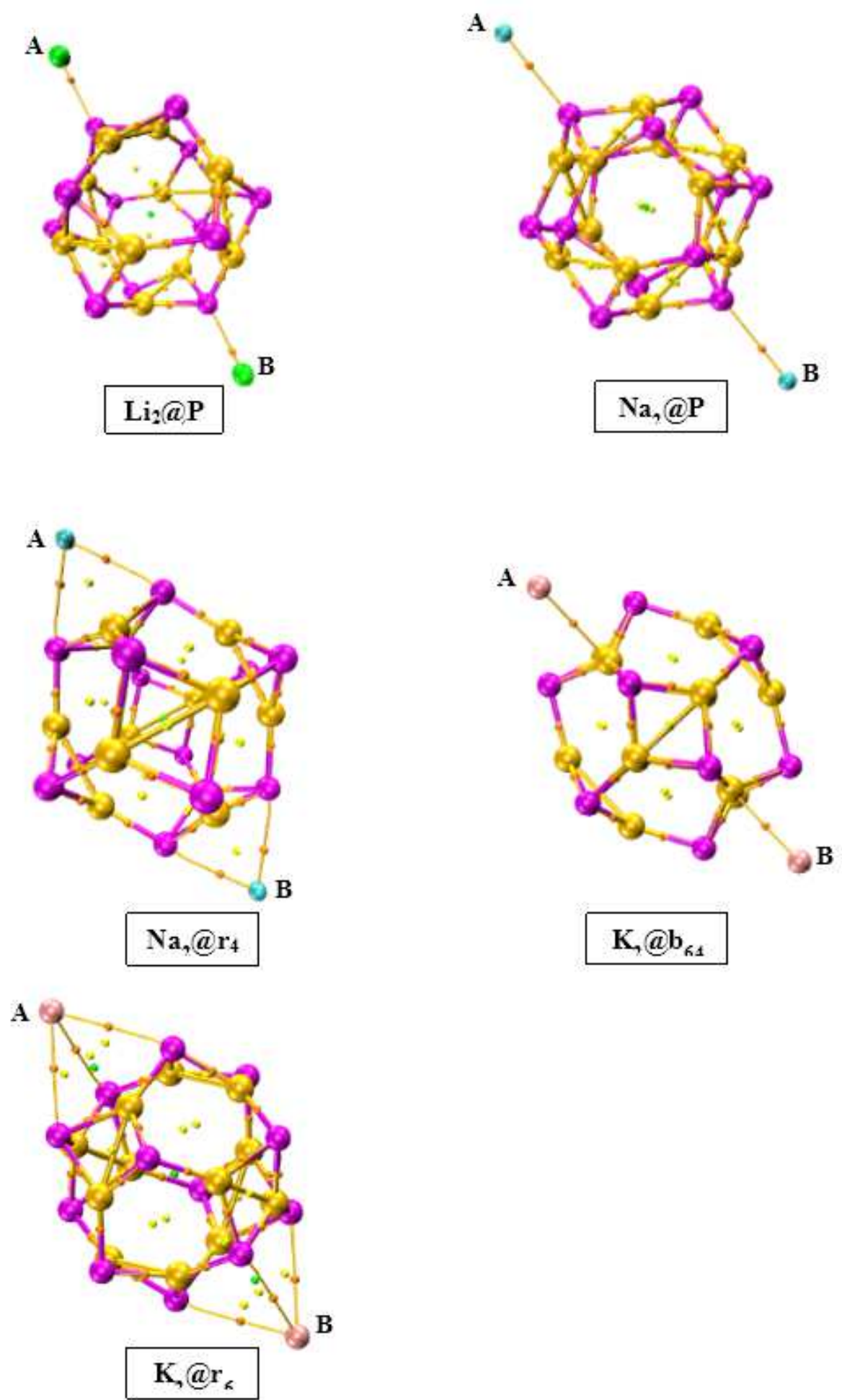

Figure 7

QTAIM analysis of bi-metal decorated B12P12 complexes for non-covalent interactions.

\section{Supplementary Files}

This is a list of supplementary files associated with this preprint. Click to download. 
- Supportinglnformation.docx 